\title{
Uma Análise do Impacto da Filosofia Ágil do Scrum no Sucesso de Projetos de Software
}

\author{
Raaby Miranda ${ }^{1}$, Diovanni Araújo ${ }^{1}$, Carlos Portela ${ }^{1}$, Albert Lopes ${ }^{1}$ \\ ${ }^{1}$ Faculdade de Sistemas de Informação/Universidade Federal do Pará (UFPA) \\ \{raabyafonsomiranda, albert.richard\}@gmail.com, \{diovanni, csp\}@ufpa.br
}

\begin{abstract}
Many researches deal with the values and principles of agile methodologies. Philosophy is the basis for the main practices proposed by these methodologies. However, few studies deal with the impact of agile philosophy on success/failure of a software project. This paper presents an analysis of student learning in academic software projects that follow the practices and values of the Scrum framework. We seek to qualitatively analyze the impact of commitment, communication and teamwork on the outcome of these software projects through a case study. The results of this research suggest that the absorption of these values by the teams impacts directly on the follow-up of the practices of Scrum and, consequently, on the success of the project.
\end{abstract}

Resumo. Ao iniciar os estudos sobre metodologias ágeis, muitos trabalhos falam sobre os seus valores e princípios. A filosofia é a base para as principais práticas propostas por essas metodologias. Mas qual o impacto da filosofia ágil no sucesso/falha de um projeto de software? Este artigo apresenta uma análise da aprendizagem dos alunos em projetos de software acadêmico que seguem as práticas e os valores do framework Scrum. Em particular, busca-se analisar qualitativamente o impacto do comprometimento, comunicação e trabalho em equipe no resultado desses projetos de software através de um estudo de caso. Os resultados desta pesquisa sugerem que a absorção desses valores pelas equipes impacta diretamente no seguimento das práticas do Scrum e, consequentemente, no sucesso do projeto.

\section{Introdução}

O uso de metodologias ágeis requer entendimento de valores e princípios, pois a filosofia é a base para as principais práticas propostas por essas metodologias. Essa filosofia é compreendida e incorporada pela equipe durante o projeto de software. Desta forma, valores humanos estão intrínsecos neste processo.

Este trabalho apresenta, no ambiente acadêmico, um olhar sobre os valores humanos e filosóficos envolvidos durante o trabalho em equipe no gerenciamento ágil de projetos. Os resultados obtidos nesta experiência são analisados e relatados com base nos pressupostos teóricos do manifesto ágil, elaborado por Beck et al (2001).

\subsection{Identificação do Problema}

O uso de uma abordagem ágil em processos de desenvolvimento de software não é trivial. Para Pressman (2010), as metodologias ágeis foram desenvolvidas com o objetivo de vencer as fraquezas percebidas e reais da Engenharia de Software, como demora na 
entrega, falta de feedback ao cliente, custos elevados, etc. Porém, existem aspectos do desenvolvimento do projeto que ultrapassam os limites técnicos, como o valor humano.

Pessoas são diferentes e interagir uma com as outras em sintonia para atingir um objetivo em comum requer grande experiência, motivação e orientação. Conhecer os valores e princípios filosóficos da metodologia ágil Scrum é diferente de assimilá-los e aplicá-los no dia a dia. Jeff Sutherland (2014), em seu livro "Scrum: A Arte de fazer o dobro do trabalho na metade do tempo", apresenta o Scrum de uma forma mais abrangente, não somente focado na área de software, mas como ponto importante na parte de gestão de pessoas para a melhoria do processo como um todo.

Assim, a problemática identificada nesse contexto é entender como a filosofia ágil impacta no sucesso de um projeto de desenvolvimento de software no contexto acadêmico. Trabalhos como os de Mahnic (2012), Coupal e Boechler (2005) e Rico e Sayani (2009) enfatizam a melhoria de equipes em projetos de software no âmbito acadêmico, comparando-os com o processo tradicional. O trabalho de Pereira (2018) relata um mapeamento de problemas encontrados durante a execução de um projeto, sendo um deles a equipe do projeto, o qual mostra que a falta de comunicação, colaboração, empatia, motivação e experiência pode comprometer todo o processo.

\subsection{Objetivo da Pesquisa}

Esta pesquisa objetiva analisar a aprendizagem dos alunos em projetos de software acadêmico que seguem as práticas e valores do framework Scrum. Em particular, buscase analisar qualitativamente o impacto do comprometimento, comunicação e trabalho em equipe no resultado desses projetos de software através de um estudo de caso.

A escolha do Scrum é baseada na definição de Schwaber e Sutherland (2013, p. 3 ), os quais caracteriza-o como um arcabouço de recursos e modelos para gerenciamento de projetos, podendo empregar outros processos ou técnicas, adaptando-o à realidade da equipe e/ou projeto. Estes projetos, nesse caso de estudo, possuem as limitações de experiência dos estudantes no contexto acadêmico e do tempo de duração das disciplinas.

Baseado nesta experiência acadêmica e na análise dos trabalhos relacionados, nós temos a seguinte pergunta de pesquisa em relação à problemática apresentada: Qual o impacto da absorção dos valores do Scrum no seguimento de suas práticas e, consequentemente no sucesso do ensino em gestão de projeto de software?

\section{Filosofia Ágil}

\subsection{Fundamentação Teórica}

No ano de 2001, um grupo de profissionais na área de Engenharia de software se reuniu com o intuito de melhorar o desenvolvimento de softwares. O encontro originou o Manifesto Ágil (Beck et al, 2001).

O desenvolvimento ágil é um termo utilizado para um conjunto de métodos e práticas baseados nos valores e princípios expressos no manifesto. Há pontos comuns a estes métodos, como por exemplo equipes pequenas, menos hierarquia, ciclos curtos, iterativos e 
incrementais, foco no valor, entre outros. Porém, dentre estes, destaca-se o Scrum, que abrange ser mais que uma metodologia, se caracterizando como um framework ${ }^{1}$.

Valores adicionais do Scrum, como o trabalho em equipe, comprometimento e comunicação foram criados tendo como pilar os valores do manifesto ágil. A equipe Scrum de um projeto é pequena, desta forma, seus membros devem interagir e se comunicar frequentemente para realizar as tarefas. Trabalhar em equipe é considerado essencial para o sucesso do projeto. Assim, a responsabilidade sobre o trabalho não é individual, e sim coletiva (Sabbagh, 2013).

O comprometimento diz respeito a estar vinculado com o trabalho e com as pessoas da sua equipe por vontade própria, estar empenhado em realizar as atividades e entregar os produtos de trabalho no prazo, atingindo metas (Gripp 2016). A comunicação deve merecer atenção especial em qualquer relação de trabalho envolvendo grupo de pessoas. Nas práticas ágeis, a busca pela comunicação dentro da própria equipe e com os clientes, propicia compartilhamento de informações e recursos de extrema importância para a execução do projeto.

Segundo Sabbagh (2013), o Scrum não define práticas e passos a serem seguidas criteriosamente, prescreve apenas três papéis (Product Owner, Equipe Scrum e Scrum Master), seis eventos (Sprint e reuniões de Sprint Planning, Daily Scrum, Sprint Review e Sprint Retrospective) e três artefatos (Product Backlog, Sprint Backlog e o Incremento do Produto).

O ciclo do Scrum tem o seu desenvolvimento e desempenho baseados em iterações (sprints) realizadas ao longo de todo o desenvolvimento do projeto. A Figura 1 ilustra o ciclo de desenvolvimento Scrum simplificado para a disciplina, com os seus principais eventos e envolvidos.

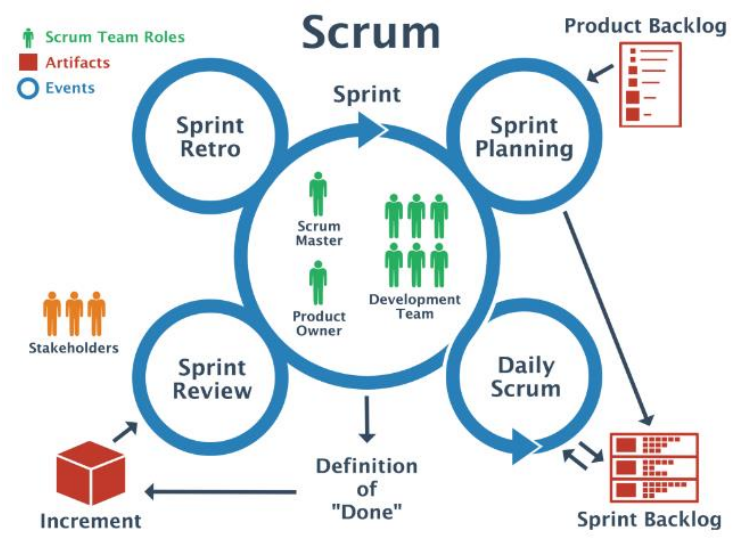

Figure 1. Ciclo de Vida do Scrum.

Inicialmente, o Product Owner define o Product Backlog que especifica as funcionalidades desejadas para o sistema, geralmente, através de User Stories. Em seguida, a Equipe Scrum inicia o Sprint Planning, selecionando quais stories serão desenvolvidas na Sprint. Estas stories irão compor o Sprint Backlog. Assim, inicia-se os ciclos de desenvolvimento, onde a equipe codifica e testas as funcionalidades do software. Durante esse período, realizam-se daily scrum para monitoramento do andamento das atividades e da identificação de impedimentos.

\footnotetext{
${ }^{1}$ Uma estrutura para servir de suporte e guia para a construção de softwares
} 
Após a equipe atender as definições de pronto das stories da sprint, marca-se a Sprint Review para apresentar o incremento de software gerado. Ao final, a equipe realiza uma Retrospective para avaliar o que deu certo, o que deu errado e o que pode melhorar para a próxima interação.

\subsection{Scrum no Ensino}

A imersão de metodologias de desenvolvimento ágil em ambientes acadêmicos vem sendo empregada como forma de estimular a difusão ampla no aprendizado em salas de aula, permitindo desta forma um aprofundamento maior nas disciplinas que trabalham com o tema, como Engenharia de Software (Silva et al. 2016).

Temos como benefício dessa prática a introdução direta dos alunos em atividades reais, capazes de estimular competências especificas, aproximando-os das possíveis situações corrente no mercado de trabalho. Sob essa perspectiva, a metodologia Scrum apresenta-se como uma alternativa para práticas pedagógicas (Rocha, Sabino e Acipreste 2015).

Em Rocha, Sabino e Acipreste (2015) foi realizada uma investigação empregando o Scrum como prática pedagógica com alunos da disciplina de Engenharia de Software em um curso técnico de informática. O objetivo foi analisar o desempenho dos alunos na disciplina com Scrum, além de verificar a percepção dos estudantes sobre o ensino deste framework, assim como os pontos positivos e negativos da aplicação do Scrum na didática. Para coleta de dados, os autores aplicaram questionários e observaram que os principais aspectos foram o trabalho em equipe, o autogerenciamento, o desenvolvimento através de práticas ágeis e o compartilhamento de ideias.

Silva et al. (2016) propõem uma análise dos resultados da utilização do Scrum como método ágil de desenvolvimento, em uma turma do curso técnico em Informática de uma Instituição de Educação Profissional. As atividades realizadas envolveram a construção de um software funcional de um cliente real. Capacidades essenciais para formação técnica dos alunos foram analisadas como escolha e aplicação de ferramentas ágeis, tomada de decisões e resolução de conflitos, entrega de versões intermediárias, trabalho em equipe e análise das etapas que compreendem o processo de desenvolvimento.

Andrade, Brito e Lima (2016) relatam a experiência com a metodologia ágil Scrum em sala de aula como parte de um projeto de desenvolvimento da disciplina Engenharia de Software. Aplicou-se um questionário para colher informações dos alunos sobre pontos fracos e fortes, ameaças e oportunidades. Com a estratégia utilizada, foi possível observar os pontos positivos do desenvolvimento com Scrum e os pontos negativos relacionados a prática e falta de conhecimento por parte dos alunos.

Em Nascimento e Rodrigues (2017), os autores propuseram a utilização do Scrum durante a disciplina de Desenvolvimento Web. Uma das principais características analisadas foi a interação na equipe, dando destaque a comunicação e trabalho em equipe.

Por fim, é possível perceber que existem diversos trabalhos de pesquisa relacionados ao uso do Scrum em sala de aula, principalmente na disciplina de Engenharia de Software. Todavia, nenhum desses trabalhos enfatiza o impacto dos valores do Scrum e do Manifesto Ágil no sucesso/fracasso do projeto de software. 


\section{Estudo de Caso}

Esta pesquisa foi realizada em duas turmas de graduação, durante as disciplinas de Estrutura de Dados II (EDII) e Gerência de Projetos de Software (GPS) do curso de Bacharelado em Sistemas de Informação da <omitido para revisão>. Desta forma, envolveu 52 alunos e 2 professores. As disciplinas foram ofertadas no segundo semestre de 2018, nos meses de Novembro e Dezembro.

A disciplina de EDII objetiva lidar com as formas de representações e manipulações dos dados, que mudam em função do cenário onde estão inseridos. Acerca dos tópicos, abordar-se: Árvores e Percursos em Árvores; Árvores de Busca; Grafos e Percursos em Grafos; Tabela de Hash. Já a disciplina de GPS objetiva apresentar os aspectos gerais e características de projetos de software de forma teórica e prática. Acerca dos tópicos, aborda-se: Aspectos Gerais e Características do Projeto; Abordagem por Fases e Etapas de um Projeto; Escopo, Tempo, Custos e Qualidade; Recursos Humanos e Comunicação; Riscos; Consolidar os conceitos em um Plano de Projeto Integrado.

Optou-se por integrar as disciplinas, dado os focos dessas: desenvolvimento e gerenciamento. Assim, os alunos da disciplina de GPS atuaram como Scrum Masters das equipes de desenvolvimento da disciplina de EDII. Todas as turmas seguiram as práticas de gerenciamento do framework Scrum listadas na Subseção 2.1.

Como a disciplina durou 3 semanas, foi realizado o seguinte planejamento das atividades, conforme mostra Figura 2.

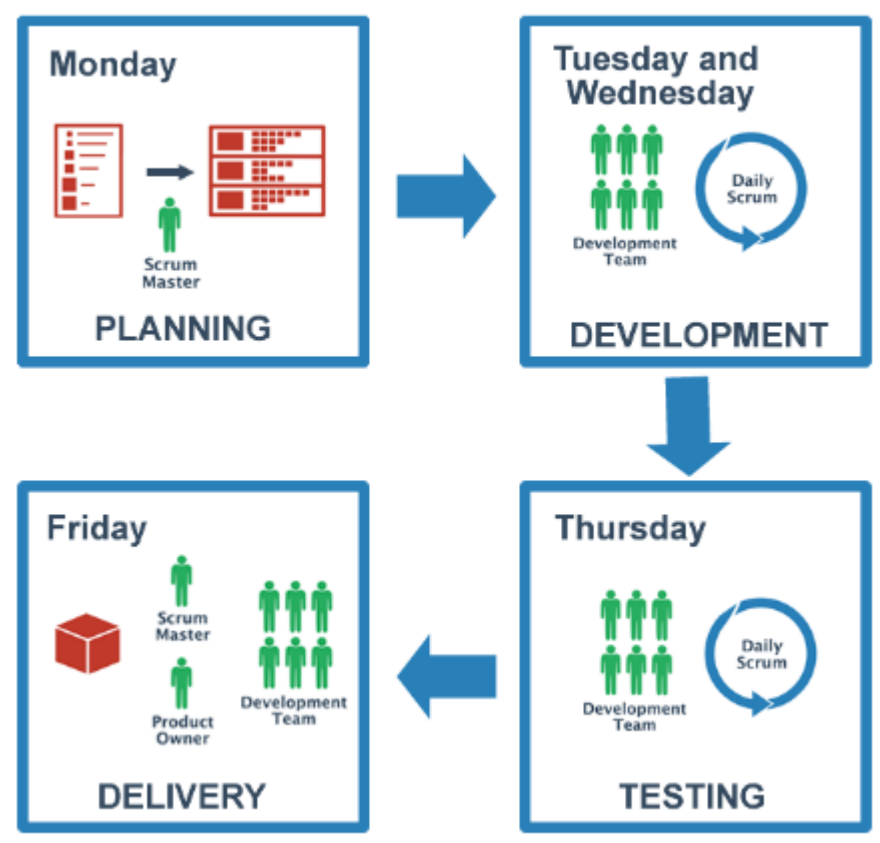

Figura 2. Scrum adaptado para o ensino da disciplina.

Toda segunda-feira, era realizado o planejamento das atividades a serem conduzidas na sprint, a partir da análise do valor de negócio das stories. Na terça e quarta-feira, a equipe ficava focada na codificação das funcionalidades do sistema. A quinta-feira foi alocada para os testes antes da apresentação. Na sexta-feira, era feita a entrega e Sprint Retrospective. 


\subsection{Papéis e Responsabilidades}

O professor da disciplina de GPS assumiu o papel de coaching, orientando os alunos selecionados para o papel de Scrum Master em suas atividades. Os Scrum Masters deveriam apoiar os times no seguimento dos eventos do Scrum e no gerenciamento do projeto.

Os Scrum Masters devem interagir diretamente com o Product Owner, que no caso foi o professor da disciplina de EDII. O Product Owner elicitava e explicava os requisitos na forma de user stories. Adicionalmente, aprovava ou reprovava a entrega da Sprint. Por fim, os Scrum Masters da disciplina GPS gerenciavam as equipes de desenvolvimento da disciplina EDII, conforme ilustra a Figura 3.

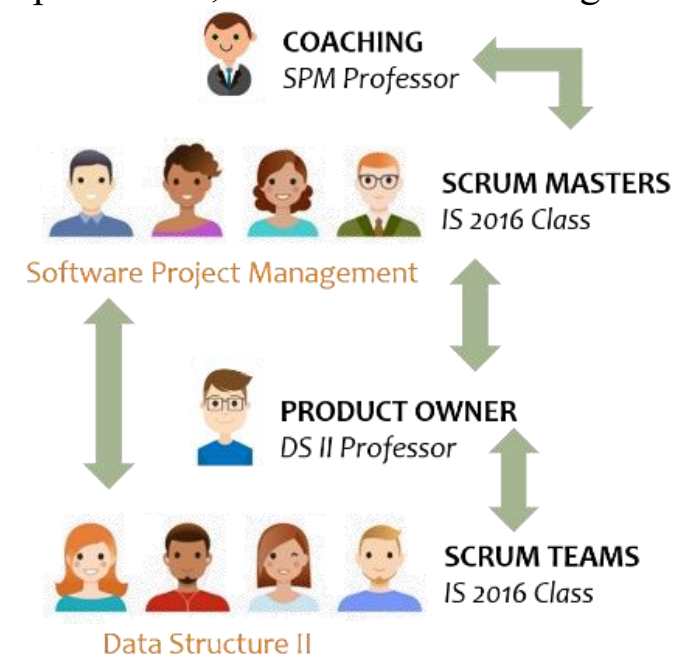

Figura 3. Scrum adaptado para a disciplina.

\subsection{Valores e Práticas}

Os professores optaram por trabalhar com 3 valores nessa pesquisa: trabalho em equipe, comprometimento e comunicação. Essa escolha levou em consideração a importância desses valores para a gerência de projetos e o tempo reduzido das disciplinas (3 semanas).

Quanto ao trabalho em equipe, houve a integração de alunos de duas turmas distintas, onde o desempenho de uma afetava na avaliação da outra. Ambas as turmas estavam focadas em um objetivo comum: entregar um software funcional e atender à demanda do Product Owner.

Em relação ao comprometimento, os alunos deveriam atender aos objetivos das sprints (desenvolver as stories) e entregar o resultado (incremento de software) no prazo. No que diz respeito à comunicação, foram adotadas como ferramentas: o mensageiro WhatsApp para comunicação da equipe troca e o Trello para criação e atualização do quadro de trabalho. Os alunos das duas turmas se reuniam diariamente durante as aulas, pois a disciplina de EDII era ministrada pelo turno da manhã e a de GPS pela tarde.

\subsection{Execução do Projeto}

Inicialmente, os professores das duas disciplinas se reuniram para planejar o projeto integrado, antes de iniciar as aulas. Nessa etapa, os professores selecionaram o projeto e criaram os materiais de aula. $\mathrm{O}$ projeto consistiu na criação de uma rede social para conectar profissionais através de estruturas de grafos. 
$\mathrm{Na}$ primeira aula, os professores apresentaram as ementas das disciplinas e a proposta de projeto integrado. Em seguida, definiram-se 4 equipes de 13 alunos, sendo 6 scrum masters da disciplina GPS e 5 membros da equipe scrum (desenvolvedores) da disciplina EDII.

Na segunda aula, foi realizado um treinamento de 4 horas sobre o framework Scrum com as duas turmas a fim de nivelar o conhecimento dos alunos. Após esse treinamento, os professores definiram o cronograma e os prazos de entregas e avaliação, conforme a Figura 2. Assim, no total, foram realizadas 3 sprints de 5 dias úteis.

Iniciando o projeto, os alunos entrevistaram o Product Owner buscando definir a Visão do Produto. Este documento consiste numa projeção de como será o produto de software ao final do desenvolvimento. Posteriormente, criou-se o documento de Product Backlog, que registrou as funcionalidades da rede social através de User Stories. Após a criação do Product Backlog, cada equipe realizou o planejamento das suas sprints, selecionando as stories a serem codificadas de acordo com o valor de negócio atribuído pelo Product Owner.

Os professores realizaram o monitoramento das atividades do projeto e a coleta de dados da pesquisa. O monitoramento foi feito diariamente a partir da observação dos alunos em sala de aula e de reuniões constantes com os Scrum Masters das equipes. Já a coleta de dados foi feita a partir do uso de questionários estruturados em quatro (4) tópicos, são eles: Motivação, Comunicação, Papel e Contribuição. O tópico Motivação e Papel é referente ao valor trabalho em equipe, enquanto o tópico Contribuição baseia-se no valor comprometimento, e o tópico Comunicação é referente ao valor comunicação. Por fim, considerou-se na avaliação o resultado do projeto desenvolvido, com base no seu sucesso ou falha, ou seja. Nesse sentido, considerou-se: a entrega no prazo, a gestão da equipe e o valor de negócio das estórias entregues ao Product Owner.

\section{Resultados e Discussões}

\subsection{Coleta e Análise dos Dados}

Para coleta de dados foi aplicado junto aos estudantes um questionário on-line com perguntas objetivas e discursivas contemplando os valores da filosofia ágil sob quatro tópicos de análise: Motivação, Comunicação, Papel e Contribuição. Todas as perguntas foram respondidas individualmente, justamente para medir o quão de valor ágil cada membro do projeto assimilou durante o projeto. Perguntas como: "Como você avalia sua ...", "Como se sente em relação ...", reforça o foco na pessoalidade. O questionário foi aplicado ao final do semestre, após a apresentação dos softwares desenvolvidos para toda a turma, e obteve 20 respostas.

As figuras a seguir apresentam a escala de respostas sobre cada valor ágil e suas respectivas percentagens. A Figura 4 apresenta o nível de motivação para estudar GPS antes - Figura 4(a), durante - Figura 4(b) e depois - Figura 4(c) do Scrum. Observou-se que a maioria dos alunos se sentia motivado para estudar GPS sem Scrum, e 25\% estudava por obrigação. Durante a aplicação do Scrum em sala de aula, obteve-se na soma da motivação positiva $90 \%$ de aceitação. Após o uso do Scrum como elemento de ensino, obtivemos 95\% de motivação positiva, com notável aumento para o item "Muito Motivado", que aumentou de 10 para 30\%. Quando perguntados se estudariam novamente usando o ensino Scrum, $95 \%$ dos alunos responderam que sim. 


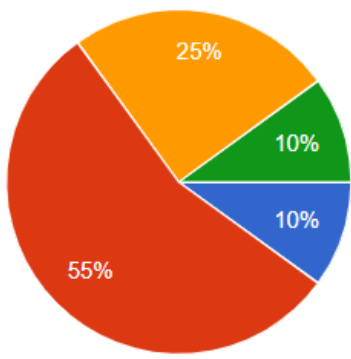

(a)

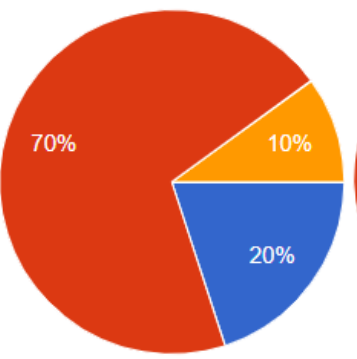

(b)

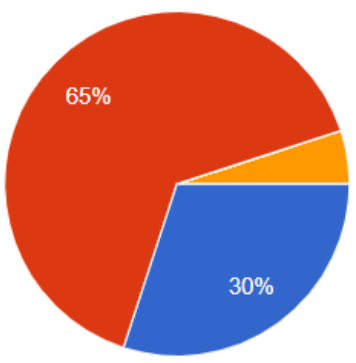

(c)

\section{Figura 4. Respostas: (a) Motivação para estudar antes do Scrum; (b) Motivação para estudar durante o Scrum; (c) Motivação para estudar depois do Scrum. Fonte: próprio (2019)}

Com relação às perguntas discursivas do valor motivação, haviam duas interrogativas: 1-“Qual é o principal benefício do Scrum para seu aprendizado?" e 2"Qual é a sua principal crítica ao Scrum em ambiente acadêmico?". A Figura 5 apresenta a nuvem de tags gerada sobre as respostas dos alunos, onde visualiza-se as palavras mais utilizadas para exprimir suas opiniões em relação a pergunta 1, Figura 5(a), e pergunta 2, Figura 5(b). Evidenciamos que o principal benefício do uso do Scrum para o ensino em ambiente acadêmico é a "melhor" "organização" de "tarefas" na "gerencia" de "equipe", palavras essas em aspas mais frequentes em meio as respostas. Em relação as críticas, observa-se um paradoxo, pois evidencia com maior frequência as palavras "ambiente", "acadêmico", "dificuldade", "comprometimento" e "tempo", ou seja, dificuldades de comprometimento da equipe e o tempo curto em ambiente acadêmico é fator de impacto na motivação. O relato de um dos alunos justifica o contexto anterior, onde diz: "...além disso, em ambiente acadêmico, os indivíduos tendem a demonstrar menor comprometimento do que em ambiente de trabalho, já que o último envolve uma remuneração.".

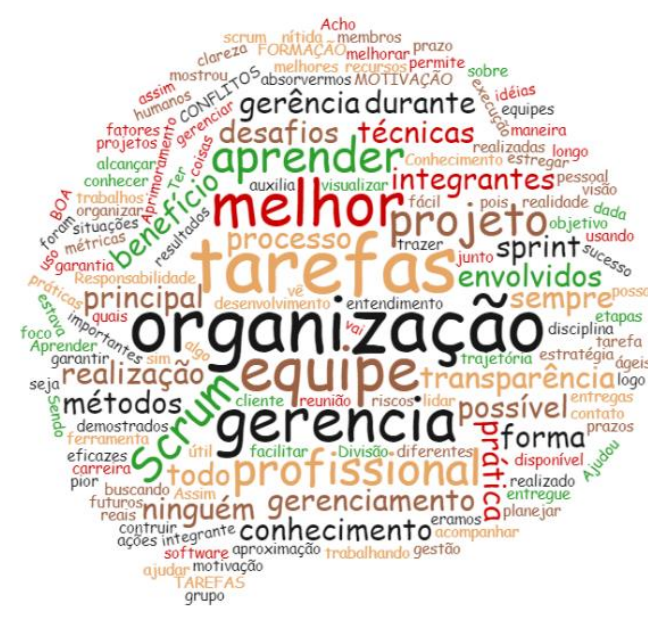

(a)

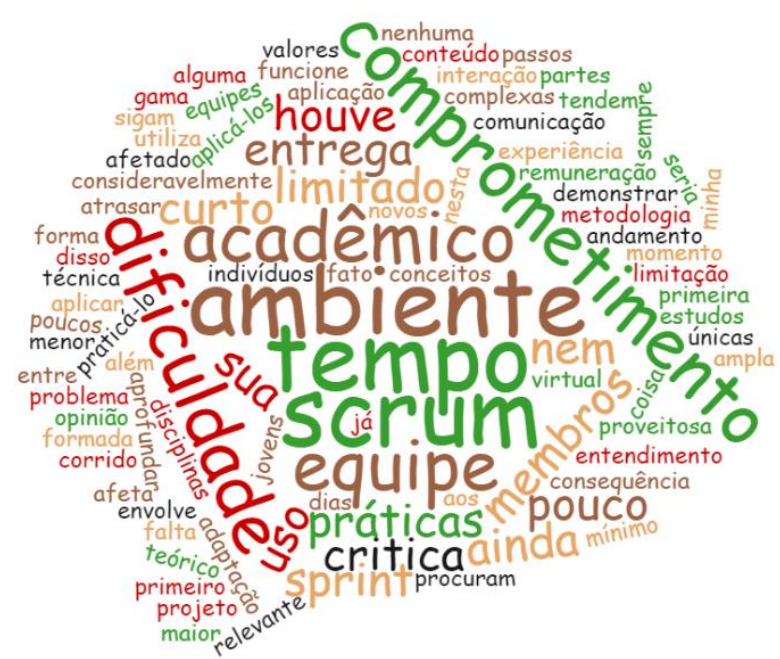

(b)

Figura 5. Nuvem de tags Motivação: (a) Pergunta 1; (b) Pergunta 2.

A Figura 6 apresenta o nível de comunicação dos alunos e da equipe. São duas perguntas objetivas: 1-“Como se sente em relação a sua capacidade de comunicação com a equipe?” e 2-“ Como se sente em relação a capacidade de comunicação da equipe?”. A 
comunicação em projetos é crucial para o sucesso, através dela equipes se organizam, resolvem problemas e impedimentos, melhoram o processo e agilizam soluções. A figura 6(a) apresenta o percentual de satisfação da pergunta 1 , com $85 \%$ de positividade e $15 \%$ de neutralidade. A Figura 6(b) apresenta o percentual da pergunta 2, com também $85 \%$ de positividade, destaque para o aumento de 5\% para $15 \%$ do item "Muito satisfatória". Percebeu-se que os alunos se sentem mais confortáveis em uma equipe comunicativa, catalisando a sua própria comunicação.

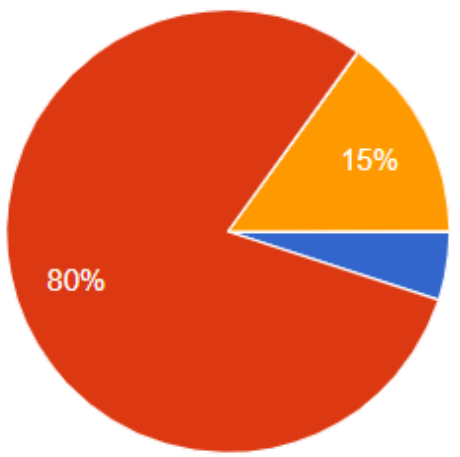

(a)

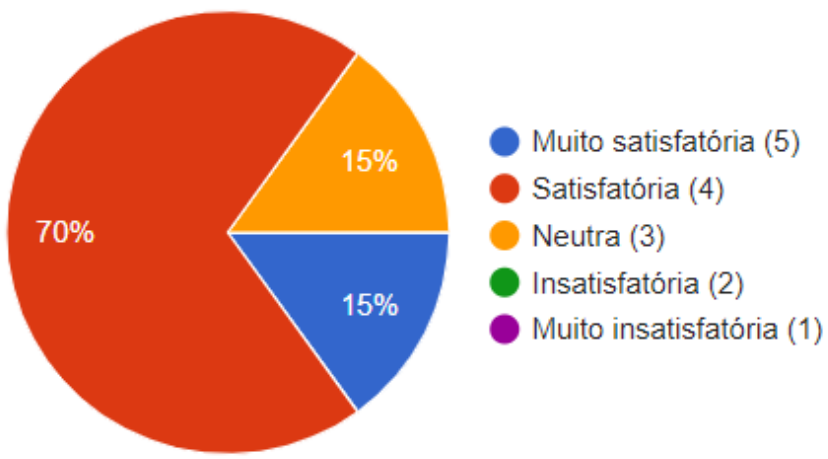

(b)

Figura 6. Respostas: (a) Satisfação da comunicação pessoal para com a equipe; (b) Satisfação sobre a comunicação da equipe.

Com relação as perguntas discursivas do valor comunicação, temos duas interrogativas: 1-“ $\mathrm{O}$ que ajudaria você a se comunicar melhor com a equipe?" e 2-“ $\mathrm{O}$ que ajudaria a equipe a se comunicar melhor?". As respostas não eram obrigatórias, portanto tivemos 15 e 16 respostas, respectivamente a cada pergunta. A Figura 7 apresenta a nuvem de tags gerada sobre as respostas dos alunos, onde visualizamos as palavras mais utilizadas para exprimir suas opiniões em relação a pergunta 1, Figura 7(a), e pergunta 2, Figura 7(b). Evidencia-se que as palavras mais frequentes para a pergunta 1 são "ter", "disponibilidade" e "integrantes", ou seja, um maior tempo dos integrantes ajudaria na comunicação. Para a pergunta 2, os alunos usam com frequência as palavras "reuniões", "membros", "equipe" e "diárias" evidenciando que a equipe se comunicaria melhor se tivesse mais tempo para reuniões diárias, com base na leitura de suas respostas.

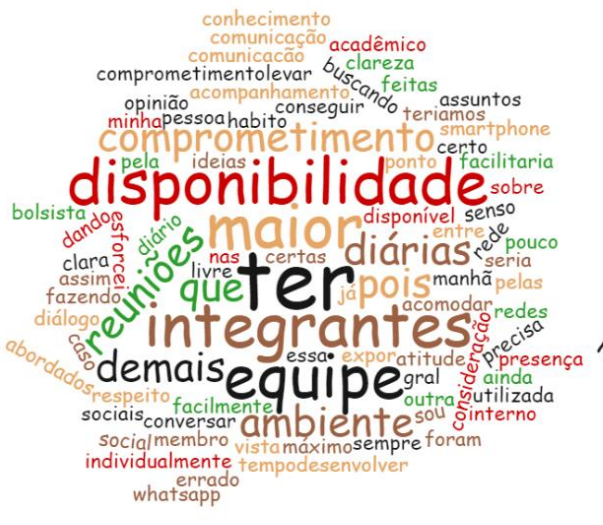

(a)

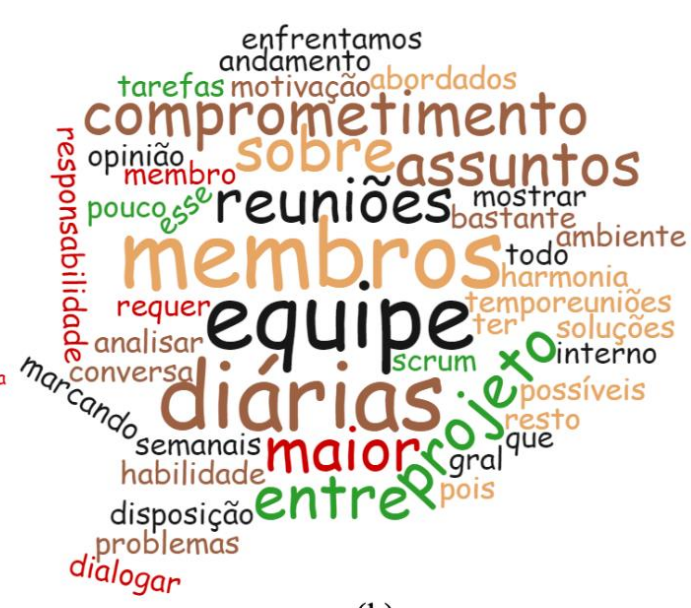

(b)

Figura 7. Nuvem de tags Comunicação: (a) Pergunta 1; (b) Pergunta 2. 
A Figura 8 apresenta o nível de importância que o aluno sente com relação a sua função (papel) e com relação a equipe. São duas perguntas objetivas: 1-“ Como se sente em relação ao seu papel na equipe?" e 2-“Como se sente em relação à equipe como um todo?". O sentimento de pertencer e ser necessário em um projeto pode impactar na saúde da equipe no processo de desenvolvimento. Esse sentimento está ligado diretamente a felicidade do integrante para com a equipe e o projeto. A Figura 8(a) apresenta o percentual de importância da pergunta 1, com 55\% para "Importante" e 35\% para "Essencial". Destaca-se negativamente o valor de 5\% para "Crucial", pois tivemos seis (6) scrum masters, papel no Scrum de importância crucial. A Figura 8(b) apresenta o percentual da pergunta 2, com 50\% para o item "Essencial" e 45\% para "Importante", mostrando a força de se trabalhar em equipe durante o ensino com Scrum.

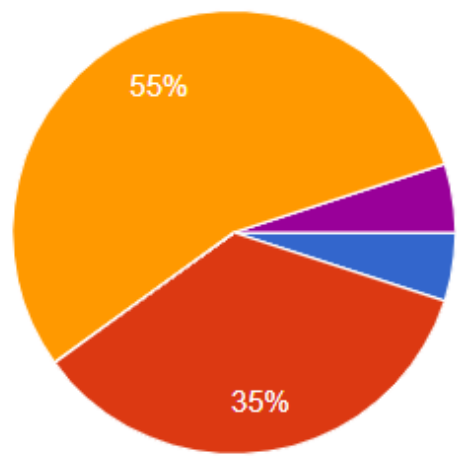

(a)

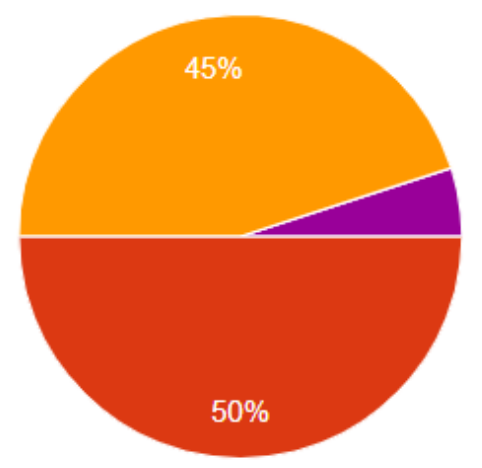

(b)
Crucial (5)

Essencial (4)

Importante (3)

Neutro (2)

Irrelevante (1)

Figura 8. Respostas: (a) Importância do seu papel na equipe; (b) Importância da sua participação na equipe como um todo.

Com relação as perguntas discursivas do valor papel, temos duas interrogativas: 1-“Por que se sente assim?" e 2-“O que faria com que ficasse mais feliz dentro da equipe?". As respostas não eram obrigatórias, portanto tivemos 15 respostas para cada pergunta. A Figura 9 apresenta a nuvem de tags gerada sobre as respostas dos alunos, onde visualizamos as palavras mais utilizadas para exprimir suas opiniões em relação a pergunta 1, Figura 9(a) e pergunta 2, Figura 9(b).

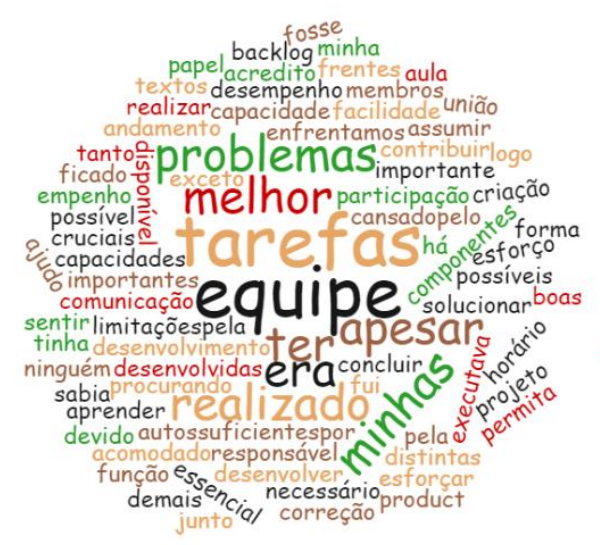

(a)

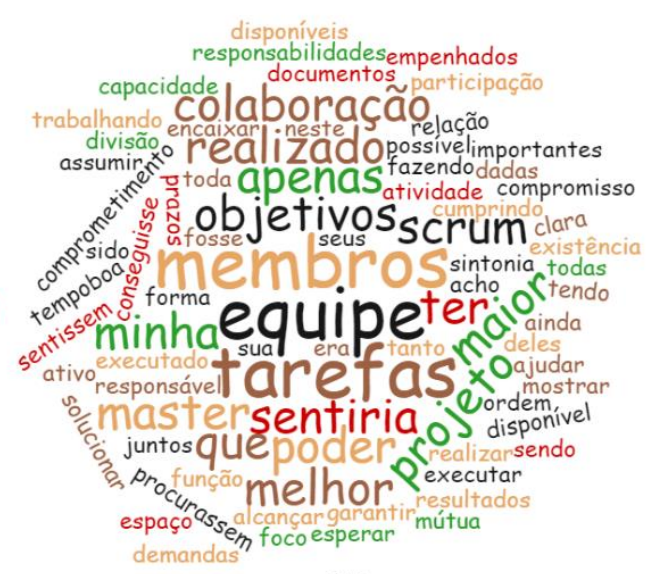

(b)

Figura 9. Nuvem de tags Papel: (a) Pergunta 1; (b) Pergunta 2. 
Observa-se que a nuvem é mais densa, refletindo em uma maior quantidade de palavras por resposta, além de uma maior diversidade de palavras, caracterizando sentimentos diversos dentro da equipe. Ambas as respostas tiveram a palavra "equipe" e "tarefas" como ponto central, evidenciando que houve um desejo de melhorar seus desempenhos nas tarefas e seus relacionamentos com os membros da equipe.

A Figura 10 apresenta o nível de contribuição que o aluno avaliou o seu trabalho no projeto, além de mensurar o impacto das atividades dos outros membros. São três perguntas objetivas: 1-“Como você avalia o resultado obtido pela equipe?", 2-“Em sua visão, qual é o impacto de suas contribuições para o resultado da equipe?” e 3-“ Em sua visão, qual é impacto das contribuições dos demais colegas da equipe no resultado?". Na Figura 10(a), relativo a pergunta 1, temos um percentual de $60 \%$ para "Satisfatório" e $30 \%$ para "Muito Satisfatório", mostrando o quão foi bem-sucedido a execução do projeto. A Figura 10(b), relativo a pergunta 2, é auto avaliativa de cada membro da equipe, e a maioria (55\%) considera sua contribuição "Importante" para o resultado final, com destaque para os $40 \%$ que consideraram "Essencial", mostrando que os membros souberam conduzir as tarefas em equipe. A Figura 10(c) apresenta a visão de cada um em relação ao desempenho dos outros, com percentuais balanceados para os itens "Crucial", "Essencial" e "Importante", mostrando empatia entre os membros e a valorização do trabalho em equipe.

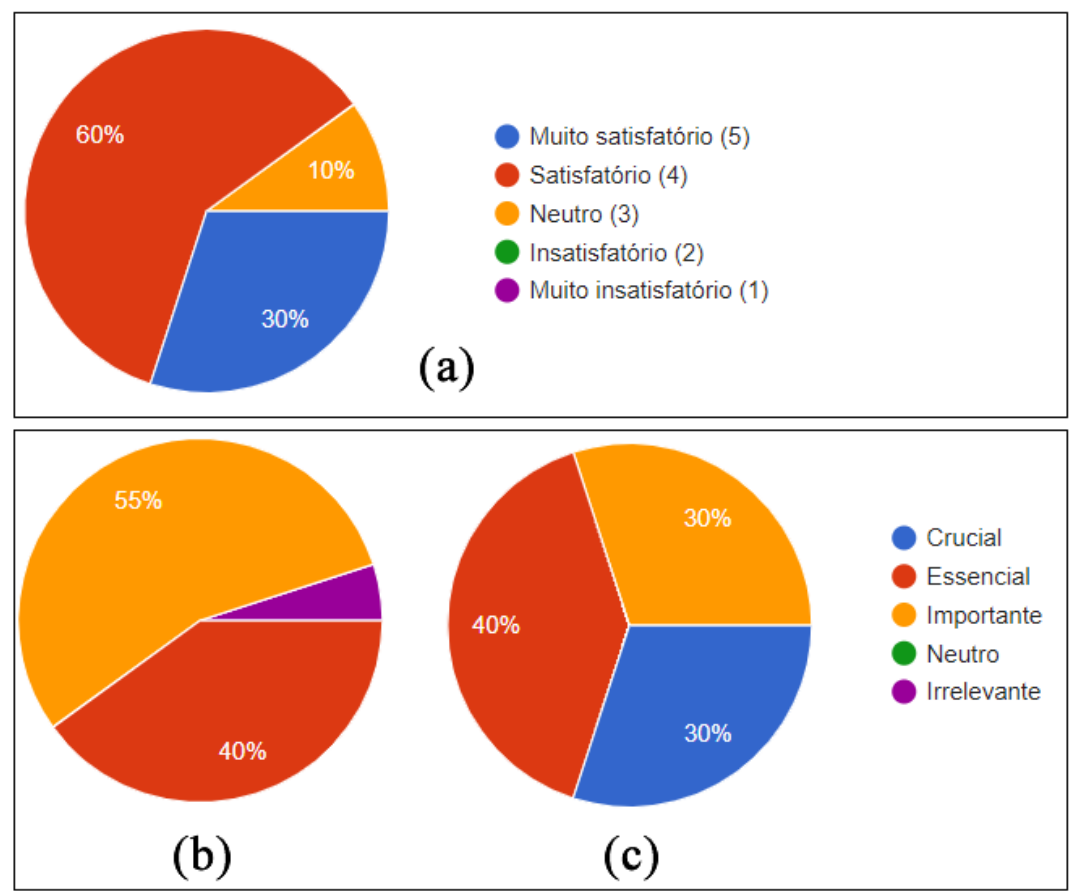

\section{Figura 10. Respostas: (a) Avaliação do resultado final da equipe; (b) Avaliação da sua contribuição para o resultado final; (c) Avaliação da contribuição dos demais membros.}

Com relação as perguntas discursivas do valor contribuição, temos quatro interrogativas: 1-“Qual foi sua principal contribuição?”, 2-“Em relação ao integrante que contribuiu menos, qual era o principal motivo para o desempenho dele?”, 3-“"Em relação aos impedimentos identificados durante o projeto, o que foi feito para resolver os mesmos?" e 4-“O que te impediu de contribuir mais ainda?”. As respostas não eram 
obrigatórias, portanto tivemos 20 respostas para a pergunta 1 e 4, e 15 para as perguntas 2 e 3. A Figura 11 apresenta a nuvem de tags gerada sobre as respostas dos alunos, onde visualiza-se as palavras mais utilizadas para exprimir suas opiniões em relação a pergunta 1, Figura 11(a), pergunta 2, Figura 11(b), pergunta 3, Figura 11(c) e pergunta 4, Figura 11(d).

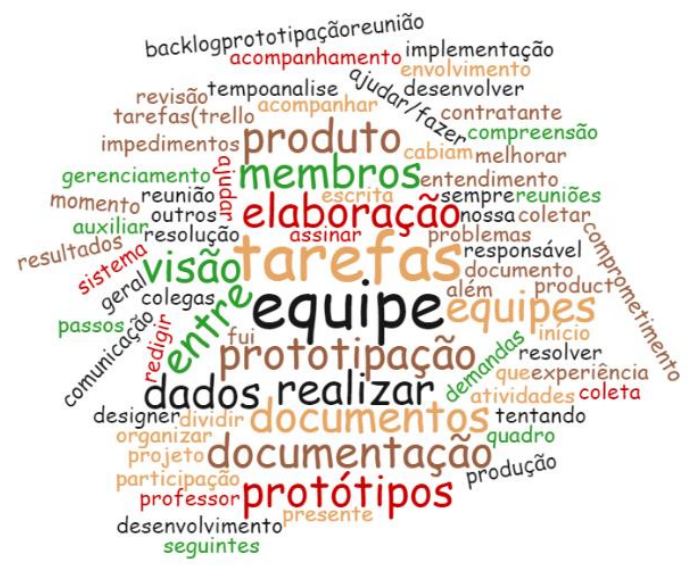

(a)

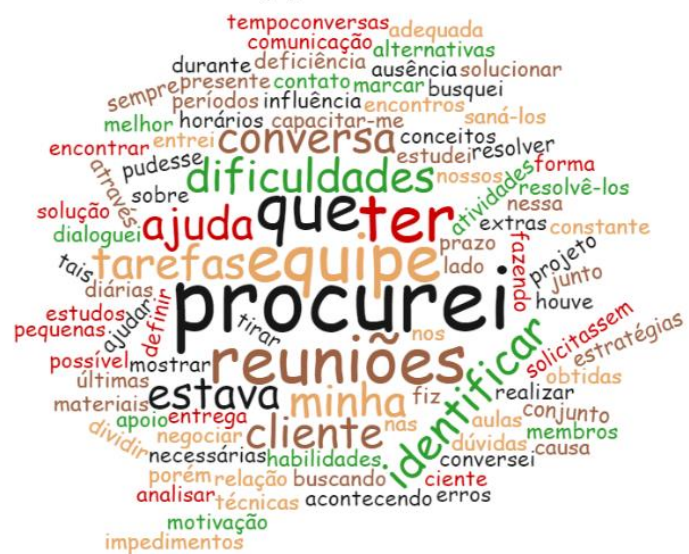

(c)

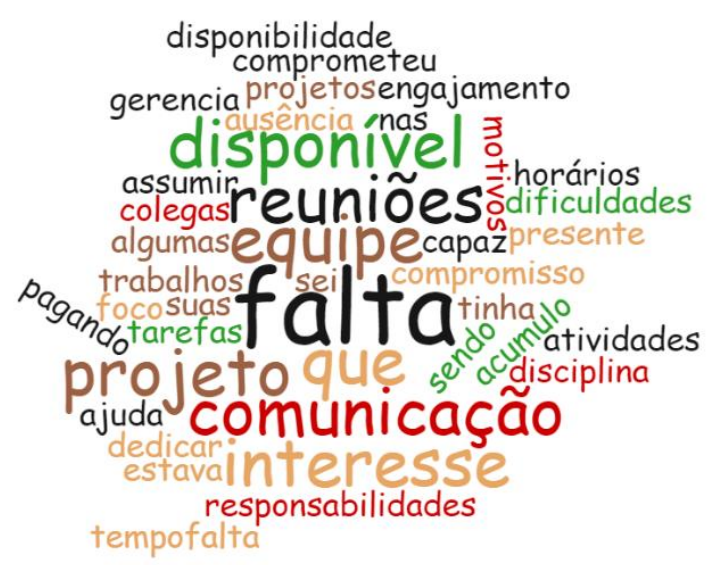

(b)

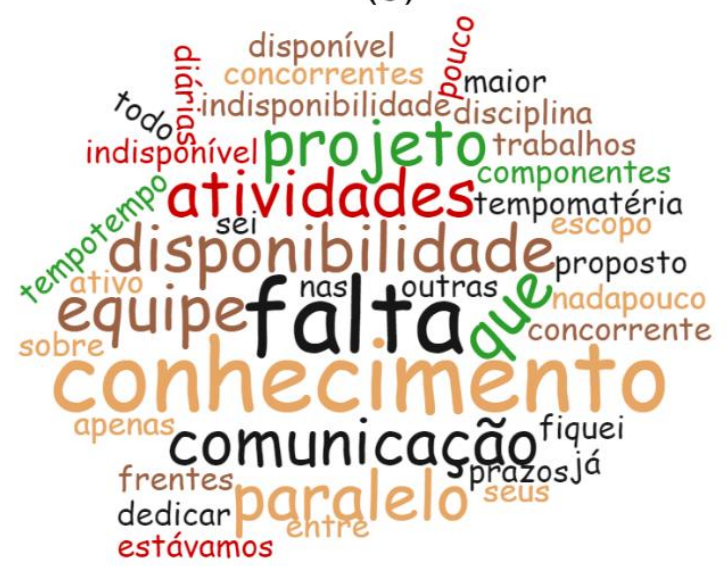

(d)

\section{Figura 11. Nuvem de tags Contribuição: (a) Pergunta 1; (b) Pergunta 2; (c) Pergunta 3; d) Pergunta 4.}

As palavras "equipe", "tarefas" e "prototipação" foram as mais frequentes nas respostas da pergunta 1 na Figura 11(a), evidenciando as tarefas realizadas na prototipação com a participação de todos. As palavras mais frequentes para a pergunta 2 na Figura 11(b) foram "disponível", "reuniões", "equipe" e "falta", evidenciando que o motivo do mal desempenho de alguns, no geral, foi devido à falta de tempo e disponibilidade dos membros em encontros e reuniões. Para a pergunta 3 na Figura 11(c), temos as palavras "dificuldades", "equipe", "tarefas", "procurei" e "reuniões" como as mais frequentes, evidenciando que os alunos tentaram resolver os problemas procurando melhorar a comunicação em reuniões, ajudar em tarefas e acabar com as dificuldades da equipe. Em relação a pergunta 4 na Figura 11(d), as palavras "falta", "conhecimento" e "disponibilidade" ocorrem com maior frequência, evidenciando os impedimentos da maioria para contribuir, barreiras como a falta de conhecimento e disponibilidade foram elementos cruciais que limitaram as equipes para alcançar seus objetivos. 


\subsection{Resultados dos Projetos}

A fim de medir o sucesso/falha dos projetos desenvolvidos, analisou-se o percentual de valor de negócio (business value) entregue ao cliente. Este valor de negócio corresponde à importância de cada User Story para o Product Owner. Neste sentido, todos os itens do Product Backlog foram estimados quanto à sua importância.

As Equipes 3 e 4, que obtiveram sucesso, entregando 71\% de valor de negócio ao cliente destacaram em suas respostas os valores de comunicação e comprometimento, evidenciado pela alta satisfação nas Figuras 6(a) e 6(b), com 85\% de positividade, e pela alta contribuição observado na Figura 10(a). A contribuição pode ser entendida como um valor de comprometimento, pois a avaliação mede o quanto cada membro participou do projeto. Quanto à comunicação, informaram que realizaram durante todo o projeto reuniões diárias (daily scrum) e usavam ativamente o grupo Whatsapp do projeto. Quanto ao comprometimento, após especificarem as tarefas técnicas do projeto, todos os responsáveis assinaram o planejamento a fim de explicitar que estavam de acordo com o mesmo.

Já as Equipes 1 e 2, que falharam, pois entregaram, respectivamente, 39 e 22\% de valor de negócio ao cliente, citaram que a comunicação e trabalho em equipe não foi efetiva, evidenciado pelas Figura 7(a) e 7(b), no qual as nuvens de tags apresentam a falta de disponibilidade para reuniões e tarefas como principal fator de insucesso, e pelas Figuras 8(a), 8(b), 9(a) e 9(b), no qual os gráficos e nuvem de tags do valor Papel apresentam críticas negativas quanto ao sentimento e felicidade do papel assumido dentro da equipe, seja pela incapacidade de concluir a tarefa ou pela falta de tempo. Quanto à comunicação, houveram relatos de que a equipe de desenvolvimento informara que as tarefas técnicas estavam prontas, porém no dia da entrega descobriram que nada havia sido realizado. Isso também demonstra a falta do valor comprometimento. Em relação ao trabalho em equipe, ocorreu individualismo, dos membros da equipe que sabiam codificar na linguagem de programação exigida pelo professor de EDII. Esses membros acabaram por centralizar as atividades e culpar os demais por estarem ociosos. A falta de visão e empatia foram as principais barreiras para alcançar o sucesso em seus projetos.

\section{Considerações Finais}

Esta pesquisa realizou um estudo de caso com duas turmas de graduação, a turma de EDII e de GPS. O objetivo principal foi analisar o impacto do uso da filosofia ágil do Scrum no sucesso de um projeto, aplicando valores e práticas no ensino da disciplina GPS. A metodologia de execução seguiu os moldes do ciclo de vida do Scrum. Além das observações realizadas durante o dia a dia da disciplina, foi realizado a coleta e análise de dados através de questionário on-line.

Os resultados parciais desta pesquisa sugerem que a absorção desses valores pelas equipes impacta diretamente no seguimento das práticas do Scrum e, consequentemente, no sucesso do projeto. Os valores trabalho em equipe, comprometimento e comunicação são cruciais e indissociáveis para o desenvolvimento do projeto e para a produção do valor de negócio, evidenciado pelo sucesso das equipes 3 e 4, com êxito na absorção desses valores, e pelo insucesso das equipes 1 e 2, com falha no processo de absorção.

Analisando os detalhes em comum com os grupos do sucesso e do insucesso, ambos se sentiram mais motivados em estudar as disciplinas com a abordagem ágil do scrum, reforçando-o como metodologia de ensino (Wijnands, 2019). Entretanto, o que era para 
ser ágil, adequado para uma disciplina de curto período, acabou por ser uma limitação devido a quantidade de tarefas, falta de experiência e de autonomia. As tarefas não foram tão complexas, porém se tornaram devido à falta de conhecimento e experiência dos alunos, fator bem comum em meio acadêmico, além da baixa autonomia de muitos membros. Contudo, duas equipes realizaram a maioria dos sprints e product backlog.

O caminho do sucesso em um projeto é sem dúvida o comprometimento. Uma equipe comunicativa é capaz de vencer obstáculos e as limitações individuais. O foco e felicidade é essencial e evidenciamos no tópico Papel, onde transpareceu as inquietudes de cada aluno. A falta de empatia e a necessidade de transpor o fracasso são os maiores danos que se pode ter dentro de uma equipe de projeto, evidenciado na pergunta sobre a contribuição dos demais membros para o resultado final, amenizado pelas perguntas auto avaliativas, onde confronta-se a realidade de aceitar o próprio fracasso. Não à toa, a metodologia ágil requer tempo, dedicação e experiência por parte da equipe e seus membros.

\section{Referências}

Andrade, B. A. L; Brito, Moara Sousa; Lima, C. (2016) Metodologia Ágil Scrum em uma Disciplina de Engenharia de Software. V Congresso Brasileiro de Informática na Educação (CBIE 2016), Anais do XXII Workshop de Informática na Escola (WIE 2016).

Beck, K., Beedle, M., Van Bennekum, A., Cockburn, A., Cunningham, W., Fowler, M., ... \& Kern, J. (2001). Manifesto for agile software development. Retrieved from http://www.agilemanifesto.org/

Coupal, C. Boechler, K. (2005). Introducing agile into a software development Capstone project. Agile Development Conference (ADC'05), 289- 297.

Gripp, A. (2016). Compromisso: Um dos principais valores do Scrum. https://www.lambda3.com.br/2016/07/compromisso-um-dos-principais-valores-doscrum/, jan, 2019.

Mahnic, V. (2012). A capstone course on agile software development using Scrum. IEEE Transactions on Education, 55(1), 99-106.

Nascimento, M. S; Rodrigues, J. P. (2017) Scrum aplicado ao desenvolvimento do software em disciplinas de desenvolvimento WEB. Revista Diálogos Acadêmicos, Fortaleza, v. 6, n. 1, jan./jun.

Pereira, J. C. (2018). Aplicação do Design Thinking Integrado com Métodos Ágeis na Gestão de Projetos de Software. Dissertação de Mestrado. Universidade Nove de Julho (UNINOVE). 152p.

Pressman, R. S. (2010). Engenharia de Software. McGraw-Hill. $6^{a}$ edição.

Rico, D. F. e Sayani, H. H. (2009). Use of Agile Methods in Software Engineering Education. Agile Conference. 174- 179.

Rocha, F. G. Sabino, R. F. e Acipreste, R. H. L. (2015). A metodologia Scrum como mobilizadora da prática pedagógica: Um olhar sobre a engenharia de software". in: Fórum de educação em engenharia de software, Belo Horizonte.

Sabbagh, R., 2013. Scrum gestão ágil para projetos de sucesso. São Paulo: Casa do Código, ISBN 978-85-66250-10-7. 
Schwaber, K. e Sutherland, J. (2013). Um guia definitivo para o Scrum: as regras do jogo. Disponível em: < http://www.scrumguides.org/docs/scrumguide/v1/Scrum-GuidePortuguese-BR.pdf>. Acesso em: 19 jan. 2019.

Silva, et al. 2016. Utilização do Scrum como Recurso Educacional no Processo de Aprendizagem em Engenharia de Software. International Journal of Alive Engineering Education, 87-102.

Sutherland, Jeff. Scrum: A arte de fazer o dobro do trabalho na metade do tempo. São Paulo: Leya, 2014.

Wijnands, W. e Stolze, A. (2019). Transforming Education with eduScrum. In: Parsons, D., MacCallum, K. (Orgs.). Agile and Lean Concepts for Teaching and Learning: Bringing Methodologies from Industry to the Classroom. 1.ed. Singapore: Springer, 2019. cap.5, p.95-114. 